\title{
Girl Body Composition according to pubertal status. Methodology variation
}

\section{DOI: http://doi.org/10.26758/8.1.16}

Consuelo Prado (1), Dolores Marrodan (2), Paula Acevedo (1), Margarita Carmenate (1)

(1) Department of Biology, University Autónoma of Madrid

(2) Department of Zoology and Anthropology, University Complutense of Madrid

Address to correspondence: Consuelo Prado, Departamento de Biología. Facultad de Ciencias. Darwin s/n. Campus de Cantoblanco. Universidad Autónoma de Madrid. 28049 Madrid, Spain. Ph: 34-914972611; Fax: 34-914978344; mail: consuelo.prado@uam.es

\begin{abstract}
Objectives. During puberty, important somatic changes that alter body composition take place. In girls, the production of ovarian estrogen generates an important metabolic change. The objective of the present paper is to analyze the differences in body composition among pre and post-menarche girls of the same chronological age, studying the variations with different methodologies.

Material and methods. The representative sample was composed of 249 schoolgirls, aged 12-13 years, who studied in "Tres Cantos" (Madrid). Two groups were formed with and without menarche (160 and 89). Body composition has been analyzed, using different methodologies: anthropometry and tetrapolar bioelectrical impedance. Population belongs to middle and upper middle class and there are no differences attributable to socio-economic situation.

Results. The analysis shows significant differences in weight and height between pre or postmenarche girls, $41.2 \pm 4.6 \mathrm{Kg}$ versus $52.0 \pm 6.6 \mathrm{Kg}$ and $154.7 \pm 6.4 \mathrm{~cm}$ versus $161.7 \pm 5.4$. According to Cole classification, both groups show a normal level of BMI, but the BMI of menarche girls was $19.89 \pm 2.0$ while that of no menarche girls was $17.21 \pm 1.9$. Body composition shows dramatically differences, the fat percentage was $13.8 \pm 2.7$ and $22.6 \pm 5.9$ in pre and post-menarche girls, with a decline of body water at the same age, water percentage being $64.7 \pm 3.0$ in premenarche subjects versus $57.7 \pm 4.4$ in those with menarche.

Conclusions. The use of biological instead of chronological age is more useful in morphological studies and classifications among the pubertal stage population. The present study shows good correlation between the anthropometric method and bioimpedance to determine fat body composition.
\end{abstract}

Keywords: Bioelectrical impedance, puberty, body composition, anthropometry, girls.

\section{Introduction}

Adolescence is a stage between childhood and the adult phase. It is a critical phase of the vital process where great variability occurs, in terms of shape and body composition. The growth process, which had been more or less constant during the ages of 3-9 years, suffers an important acceleration that gives rise to the so-called growth spurt, manifested very clearly in stature and in the somatic individuals' setup. In girls, this stage of intense changes is marked by the revival of the hypothalamus-hipofisio-gonadal axis (Prado et al., 2009). As a result of these processes, the body 
suffers a major refurbishment and change in its composition. After this stage, the young adults of both sexes have higher mineral bone content and a lower proportion of water. Subsequently, a clear sexual dimorphism is reflected, which entails the acquisition of secondary sex characteristics for each gender and a near final size. The anthropometric assessment is the study of shape, size, composition and proportionality of the individual that allows defining variations of the complex processes such as human growth (Torres et al., 2006; Milici, 2015). Nevertheless, in physical anthropology, there is a general consensus about the desirability of new techniques to supplement the traditional anthropometric methods for a better estimation of body composition. The electrical bioimpedance is among these new techniques aimed to assess the body composition more accurate, less invasive and less expensive. For anthropometric characterization of the female youth population, this study aims to identify the impact of the new hormonal context after ovarian follicular activation and the production of estrogen in girls' body composition and to objectify the changes occurred in different body compartments, in which the mere balance size/weight is insufficient. The new somatic situation is predictive of adult health, indicating the risk of developing pathologies linked to undesirable nutritional status in the medium term.

This study's working hypothesis is that all the methods to study the girls' infanto-juvenile transition are able to effectively reveal the changes in body composition.

\section{Material and methods}

This work is part of a larger study among the adolescent population of the Tres Cantos municipality, situated at the northern periphery of Madrid City. The research was conducted between 2010 and 2016 in all the public secondary schools in this satellite city and, for the present study, all the girls of 12 and 13 years of age $(\mathrm{N}=249)$ were included.

The project resulted from signing a collaboration agreement between the departments of health and education of Tres Cantos' City Hall and the General Foundation of the University Autónoma of Madrid, Department of biology, anthropology unit. Signing the agreement called for the strict monitoring of the bioethical protocol of Helsinki (2008), by obtaining parents' informed consent for all the subjects included in the study.

Once the planned activities were carried out in each of the centers, a custom report of each student was delivered to the participants and their parents or guardians. This report included an anthropometric assessment as well as recommendations to improve their current health status.

Following the International Biological Program protocol (Weiner and Lourie, 1981), the measurements were carried out by the UAM research team with the approved and previously calibrated equipment. The tetrapolar bioimpedance of double sweep (longitudinal-transverse) model 609 of Tanita has been used. Skinfolds measurements were taken with a skinfold caliper - model Holtain (with $1 \mathrm{~mm}$ precision).

Menarcheal status was reported according to status-quo method. If the answer was positive, we asked for the age and the month when first menstruation occurred. Among the subjects of the same chronological age, the menstrual status was the classification criterion in two groups: with and without menarche.

From biceps, triceps, subscapular and suprailiac skinfolds the body density was estimated (Durning and Ramahan, 1967) and, subsequently, the fat percentage of each subject was calculated by Siri Equation. With this data, we have estimated the fat mass and fat-free mass (anthropometric method). Tetrapolar impedance gave evaluations on muscle, fat, water, basal metabolism and biological age. 
The Kolmogorov-Smirnov test was applied to find out if the variables follow a normal distribution. After that, parametric tests (t Student, ANOVAS) were used for cases in which the variable is adjusted to normal and non-parametric tests (Mann-Whitney U, Kruskal-Wallis $\mathrm{H}$ ) otherwise. Tables of contingency, correlations, and $\chi 2$ test were also used. The degree of significance of the tests was of $p \leq 0.05$.

\section{Results}

The studied population lives in the municipality of Tres Cantos, in the north area of Madrid and at a distance of $20 \mathrm{~km}$ from the capital. It is an area that includes science parks, technology industry and university population. It represents a fairly uniform environment in term of education and economic status, corresponding to middle and upper middle class. The level of education is very high among the fathers of the girls $(66 \%$ parents and $62 \%$ of the mothers having a third level education), while the occupational categories can be considered high in $57 \%$ of parents and $42 \%$ of the mothers. Generally, the family size corresponds to a nuclear family, consisting of the parents and two children. At the economic level, there was no kind of situation unfavorable for growth and development.

The Bern study $(* * * W H O, 2010)$ for the practice of physical activity of children and adolescents has observed that $21 \%$ of the girls do not practice any physical activity and that in addition, among those who do, only $29 \%$ make it often referred to in the report: 1 hour/ day.

Tobacco use is higher in comparison with male subjects of the same study (Prado et al., 2012), $82 \%$ of young women are declared non-smoker, and among those who smoke 10 cigarettes is the most frequent category $(9.4 \%)$. Alcoholic beverages are consumed primarily during weekends, although $73 \%$ declare not to consume alcohol. Analyzing the hours of rest, a deficit of 5 hours/week of sleep has been observed in the case of adolescent girls, compared to the recommended duration for children aged 12-13 years, which is 9 hours. This deficit is mainly produced during the working days of the week.

Tobacco and alcohol use is more common among girls who have already had the menarche and conversely a decline is observed among those who practice sport; a negative correlation with the hours of sleep is noted, without reaching levels of significance.

The weight status of the population corresponds to the category of normal weight (79\%), although improved situations in overweight (14\%) and low weight (7\%) were detected. The obesity was low represented (1\%) (Cole et al., 2000).

Cole classification evaluated the weight according to the chronological age. However, at puberty, in same chronological age, early and late pubertal maturity coexist, while the weight situation differs noticeably in the mentioned categories. This situation advocates the importance of analyzing somatic features by taking into consideration the status of ovarian maturation of the girls of the same chronological age.

The Kolmogorv-Smirnov test and a series of parametric tests were used to show important differences between girls with and without menarche (Table 1). A statistically significant difference of $7 \mathrm{~cm}$ in height is observed ( $\mathrm{T}$ - independent samples Student, $\mathrm{t}=8.88 ; \mathrm{gl}=247 ; \mathrm{p}<0.001$ ). Similarly, the differences in weight, of $11 \mathrm{~kg}$, are highly significative $(\mathrm{t}=15.82 ; \mathrm{gl}=247 ; \mathrm{p}<$ 0.001). There are not only differences in the direct variables, but also in the proportions. Indeed, it is interesting to note that the BMI of the girls with the menarche is statistically higher $(\mathrm{t}=3.13 ; \mathrm{gl}=$ 247; $\mathrm{p}$ < 0.05). Waist to hip ratio has been widely used in the field of epidemiology since it relates to the content of visceral fat in the body (Milici, 2015). The range suitable for women is from 0.71 to 0.85 . Both groups, with or without menarche, are in the appropriate range, but there is a significant 
difference between the values of this index, which increases in girls with menarche $(\mathrm{t}=7.14 ; \mathrm{gl}=$ 247; $\mathrm{p}<0.001)$.

Table 1. Girls' height, weight, body mass index and waist-hip index according to menarcheal status (mean and standard deviation)

\begin{tabular}{|c|c|c|}
\hline VARIABLE & NON-MENARCHE GIRLS & MENARCHEAL GIRLS \\
\hline HEIGHT $(\mathrm{cm})$ & $154.68(\mathrm{SD} \pm 6.3)$ & $161.66(\mathrm{SD} \pm 5.3)$ \\
WEIGHT $(\mathrm{Kg})$ & $41.33(\mathrm{SD} \pm 4.6)$ & $52.77(\mathrm{SD} \pm 6.5)$ \\
BMI $\left(\mathrm{kg} / \mathrm{m}^{2}\right)$ & $17.21(\mathrm{SD} \pm 1.9)$ & $19.89(\mathrm{SD} \pm 2.0)$ \\
CCI $(\mathrm{cm} / \mathrm{cm})$ & $0.76(\mathrm{SD} \pm 0.07)$ & $0.82(\mathrm{SD} \pm 0.05)$ \\
\hline
\end{tabular}

The significant increase in weight in the menarche transition has been pointed out for decades (Frish and Revelle, 1970). However, this increase in weight may not be harmonious with respect to all the components that comprise the weight status of individuals. Certainly, when the fatty component variation is analyzed, it highlights a statistically significant decrease in body density $(\mathrm{t}=2.34, \mathrm{gl}=247, \mathrm{p}<0.05)$. This decrease in body density is partly due to the significant increase of fatty tissue. There is a difference of fat (not visceral) more than $5.2 \mathrm{~kg}(\mathrm{SD} \pm 1.48)$ among girls with menarche and without $(\mathrm{t}=8.93$, gl. $=247, \mathrm{p}>0.001)$ (Table 2$)$.

Table 2. Mean values of Siri body density and fat percentage assessed by anthropometric method and tetrapolar impedance (mean and standard deviation) in pre and post-menarche girls.

\begin{tabular}{|c|c|c|}
\hline VARIABLE & NON-MENARCHE GIRLS & MENARCHEAL GIRLS \\
\hline BODY DENSITY & $1.035(\mathrm{SD} \pm 0.009)$ & $1.032(\mathrm{SD} \pm 0.010)$ \\
Kg of FAT & $7.23(\mathrm{SD} \pm 4.1)$ & $12.44(\mathrm{SD} \pm 4.9)$ \\
\% FAT (skinfolds) & $17.51(\mathrm{SD} \pm 3.9)$ & $23.58(\mathrm{SD} \pm 4.2)$ \\
\% FAT (bioimpedance) & $15.83(\mathrm{SD} \pm 2.7)$ & $22.84(\mathrm{SD} \pm 5.3)$ \\
\hline
\end{tabular}

Both percentages (estimated by skinfold thickness and by bioimpedance) show statistically significant differences between the two groups considered $(t=11.33, g l=247, p>0.001)$. The values obtained by bioimpedance are slightly lower than those obtained by anthropometrical measurements, but there are no significant differences between the two methodologies when comparing the pre and post-menarche groups. Deviations from these percentages are always higher in the group with menarche, especially with the bioimpedance determination, which could be due to the effect of variation in body composition, in particular water variation that is experienced during the menstrual cycle in women (Table 2).

If a dual-component model is considered (fat and fat-free mass, assessed by bioimpedance), the study shows that there is more fat-free mass in girls with menarche, but to relativize this percentage of body component in girls without menarche the fat-free mass represents a big fraction of the body weight (Table 3 ). The differences in the absolute values of fat-free mass are significant $(\mathrm{t}=9.53, \mathrm{gl}=247, \mathrm{p}>0.001)$, as well as the percentages of fat-free mass $(\mathrm{t}=12.0, \mathrm{gl}=247, \mathrm{p}>$ $0.001)$. 
Table 3. Mean values of fat free mass in $\mathrm{kg}$. and percentage of fat-free mass of total body weight assessed by tetrapolar impedance (mean and standard deviation) in pre and postmenarche girls.

\begin{tabular}{|c|c|c|}
\hline VARIABLE & NON-MENARCHE GIRLS & MENARCHEAL GIRLS \\
\hline Fat free mass $(\mathrm{Kg})$ & $33.77(\mathrm{SD} \pm 3.47)$ & $38.70(\mathrm{SD} \pm 2.87)$ \\
$\%$ of fat-free mass & $81.70(\mathrm{SD} \pm 4.2)$ & $74.78(\mathrm{SD} \pm 4.9)$ \\
\hline
\end{tabular}

Within the free body fat fraction, an analysis of greater precision is also possible. Thus, the content of water, bone, and muscle in the two groups of girls has been analyzed. The results of this analysis are summarized in table 4 . The free-fat body mass component has been considered as a whole $(100 \%)$ and the respective percentages that represent the bone, muscle, and water within this component have been established. All results were obtained using tetrapolar bioimpedance, same apparatus and in identical circumstances. The body composition of the girls after menarche is different in all components. It is not just a change in weight (Frish \& Revelle, 1970), or an increase in adipose tissue (Frish, 1987), it is also important to consider a decrease in water content and a logical increase in bone and muscle.

Table 4. Mean values of percentage of fat-free mass and relative percentage of water, bone, and muscle within the fat-free mass assessed by tetrapolar impedance in pre and postmenarche girls.

\begin{tabular}{|c|c|}
\hline Girls without Menarche & Girls with Menarche \\
\hline \% Fat Free Mass $=81.70(\mathrm{SD} \pm 4.2)$ & $\downarrow$ \\
$\downarrow$ & \% Fat Free Mass $=74.78(\mathrm{SD} \pm 4.9)$ \\
\hline of free mass & \% of free mass \\
Water: $64.7(\mathrm{SD} \pm 3.01)$ & Water: $57.2(\mathrm{SD} \pm 4.51)$ \\
Bone: $1.88(\mathrm{SD} \pm 0.18)$ & Bone: $2.08(\mathrm{SD} \pm 0.15)$ \\
Muscle: $33.42(\mathrm{SD} \pm 3.40)$ & Muscle: $40.52(\mathrm{SD} \pm 2.87)$ \\
\hline
\end{tabular}

Generally, in comparison with girls without menarche, those with menarche but of same chronological age present statistically significant diferences in body composition and among various components of fat-free mass: a higher percentage of bone $(\mathrm{t}=9.09, \mathrm{gl}=247, \mathrm{p}>0.001)$ and muscle mass $(\mathrm{t}=15.58, \mathrm{gl}=247, \mathrm{p}>0.001)$ but a lower percentage of water $(\mathrm{t}=14.43, \mathrm{gl}=247, \mathrm{p}>0.001)$.

\section{Discussions}

As we said when introducing the present work, the pubertal transition is characterized by major physical alterations: sexual maturation, changes in body composition, and rapid skeletal growth (Martos et al., 2010). Breast development is the first manifestation of puberty in approximately $85 \%$ of girls; the normal age for initial breast development is between ages 8 and 13 . Menarche generally occurs within 2 years from the onset of breast development (Prado, 2003). Skeletal growth is one of the most striking characteristics of puberty. Linear-growth velocity begins to increase and the peak height velocity is not attained until age 12 in girls. Lean body mass, which 
primarily reflects muscle mass, begins to increase during early puberty in both boys and girls. Fat mass increases during the late stages of puberty in girls. Sex differences in the adolescent growth spurt produce the characteristic sexual dimorphism in shape and proportions seen in young adults (Prado et al., 2014). Of course, sex differences in body composition exist before puberty, but the reason for this phenomenon is unknown (Adams Hillard, 2002). The physical changes that occur during puberty are mediated, in part, through sex steroids, insulin-like growth factor I (IGF-I), and leptin. However, data that address the extent to which concentrations of these hormones influence body composition, bone mass, and density in prepubertal girls are lacking (Chan et al., 2005).

Currently, the relationship between body composition of girls and the necessary changes for the establishment of the ovarian menstrual cycles seems undeniable. It is also a simplistic reductionism to mention critical weight, that of $47 \mathrm{~kg}$. (Frish and Revelle, 1970). Obviously, the association found between menarche and BMI is described in the revised bibliography (Kaplowith et al., 2005; Parent et al., 2003). It has been observed that girls who have an early menarche, before the age of 12, have a higher BMI, and an increased tendency to overweight or obesity. The mentioned studio of Kaplowitz points out that girls who have begun their puberty have a higher BMI than those who have not started it, and that these girls would have an increased tendency to get insulin resistance. The reproductive status is extremely sensitive to the metabolic status and to the amount of stored energy that women have. In effect, it is now well known that the adipose tissue is important to acquire and maintain the reproductive ability, a body fat percentage of 22 being critical for the maintenance of menstrual cycles (Frisch, 1987). Adipose tissue is also a source of no ovarian estrogen production by aromatization of testosterone. But other pubertal changes that occur in the body composition are less known. In the present study, by limiting the concomitant factors such as temporal variation, different ages or different environmental conditions, it has been possible to evaluate what happens in the body composition of girls with the beginning of their ovarian cycles. This study has shown that, apart from any sanitary or economic limitations, girls with menarche have different anthropometric parameters in comparison to others of the same chronological age but without menarche.

In several studies, the associating of obesity with the age of menarche has been discussed. In fact, in a longitudinal study in the Finnish population, it was revealed that a higher BMI among precocious girls remained until the age of 31 (Laitinen et al., 2001). The present work may not endorse this possibility since the significantly higher value of BMI in girls aged 12-13 and with menarche in comparison with their non-menarcheal peers is due to a more advanced global somatic status. It is noteworthy that both groups of girls are in the category of normal weight for their age. The classification of Cole et al. (2000) and Cole et al. (2007) was used to characterize the subjects' weight status. However, this classification takes into account only age intervals, disregarding the differences that pubertal stages generate within body mass components; when discussing the issue of weight standards according to age, this represents a serious limitation that needs to be addressed. The study shows a good correlation between methodologies employed to assess body composition. Although both methods recorded significant differences in body fat percentage between girls with and without menarche, bioimpedance indicated slightly lower values than the anthropometric method. Studies based on bioimpedance during the menstrual cycle have shown that this method provides different estimates along the different phases of the menstrual cycle (Prado and Delgado, 2001). This study has not taken into account the phase of the menstrual cycle in which the girls were at the time of measurement. Maybe if it had, the differences between the two methods would not have been significant. The next step of the study will be the follow-up, in their final stages of adolescence, of the most precocious girls at the onset of menstruation and the evaluation of their 
weight status and body composition to detect the persistence of an increased amount of fat or lack thereof.

\section{Bibliography}

1. Adams Hillard, P.J., 2002. Menstruation in young girls: a clinical perspective. Obstetrics and gynecology, 99(4), pp.655-62.

2. Baker, E.R., 1985. Body weight and the iniciation of puberty. Clinical Obstetrics and Gynecology, 28(3), pp.573-579.

3. Chan, J.L., Mantzoros, C.S., 2005. Role of leptin in energy-deprivation states: normal human physiology and clinical implications for hypothalamic amenorrhoea and anorexia nervosa. Lancet, 366(9479), pp.74-85.

4. Cole, J.T., Bellizzi, M.C., Flegal, M.K., Dietz, W.H., 2000. Establishing a standard definition for child overweight and obesity worldwide: international survey. British Medical Journal, 320(7244), pp.1240-3. https://doi.org/10.1136/bmj.320.7244.1240.

5. Cole, J.T, Flegal, M.K., Nicholls, D., Jackson, A.A., 2007. Body mass index cut offs to define thinness children and adolescents international survey. British Medical Journal, 335, pp.194-201 https://doi.org/10.1136/bmj.39238.399444.55.

6. Comninos, A.N., Jayasena, C.N., Dhillo, W.S., 2014. The relationship between gut and adipose hormones, and reproduction. Human Reproduction Update, 20(2), pp.153-74. https://doi.org/10.1093/humupd/dmt033.

7. Durnin, J. V. and Rahaman, M. M., 1967. The assessment of the amount of fat in the human body from measurements of skin fold thickness. British Journal of Nutrition, 21, pp.681-689.

8. Freedman, D., Kettel. K.L., Serdula, M.K., Dietz, W., Srinovasan, S.R., Berenson, G.S., 2003. The relation of menarcheal age to obesity in childhood and adulthood: the Bogalusa heart study. BMC Pediatrics, 3:3. https://doi.org/10.1186/1471-2431-3-3 @ Freedman et al; licensee BioMed Central Ltd. 2003

9. Frisch, R.E., Revelle, R., 1970. Height and weight at menarche and a hypothesis of critical body weights and adolescent events. Science, 169, pp.397-399.

10. Frisch, R.E., McArthur, J.W., 1974. Menstrual cycles: fatness as determinant of minimum weight for height necessary for their maintenance or onset. Science, 185, pp.949-951.

11. Frisch, R.E., 1987. Body fat, menarche, fitness and fertility. Human Reproduction, 2(6), pp.521533.

12. Kaplowitz, P.B, Slora, E.J., Wasserman, R.C., Pedlow, S.E., Herman-Giddens, M.E., 2005. Earlier onset of puberty in girls: relation to increased body mass index and race. Pediatrics, 108(2), pp.347-53.

13. Laitinen, J., Power, C., Järvelin, M. R., 2001. Family social class, maternal body mass index, childhood body mass index, and age at menarche as predictors of adult obesity. The American journal of clinical nutrition, 74(3), pp.287-294.

14. Martos-Moreno, G.A, Chowen, J.A., Argente, J., 2010. Metabolic signals in human puberty effects of over and undernutrition. Molecular and cellular endocrinology, 324(1-2), pp.70-81.

15. Milici, N., 2015. Sindromul metabolic şi obezitatea. Perspective antropologice (Metabolic syndrome and obesity. Anthropological perspectives). Bucureşti: Editura Academiei Române.

16. Parent, A.S., Teilmann, G., Juul, A., Skakkebaek, N.E., Toppari, J., Bourguignon, J.P., 2003. The timing of normal puberty and the age limits of sexual precocity: variations around the world, secular trends, and changes after migration. Endocrine reviews, 24(5), pp.668-93. 
17. Prado, C., Delgado, E., 2001. Un problème pour la biométrie: la variation de la composition corporelle pendant le cycle menstruel après la puberté. Biométrie humaine et anthropologie, 19(1-2), pp.71-76.

18. Prado C., 2003. La puberté: Une période de crise. In: C. Susanne, E. Rebato \& B. Chiarelli, eds. 2003. Anthropologie biologique. Evolution et biologie humaine. Bruxelles: De Boeck. pp. 503512.

19. Prado C, Marrodan M.D, Valle A., 2009. Growth and maturation. In: M.D. Cabañas, F. Esparza, eds., 2009. Compendio de Cineantropometría, Madrid: CTO. pp .243-247.

20. Prado, C., Marrodan, M.D, Calabria, V., Mendez, B., Arechiga, J., 2012. Nutritional status, variation in body composition, body water, fat and muscle in adolescents of Madrid (Spain). International Conference on Nutrition \& Growth, Paris. Web: www2.kenes.com/nutritiongrowth/pages/

21. Torres, M.A., Braga, J.A., Taddei, J.A., Nóbrega, F.J., 2006. Anemia in low-income exclusively breastfed infants, Jornal de pediatria, 82(4), pp.284-7. https://doi.org/10.2223/JPED.1511

22. Weiner, J.S., and Lourie, J.A., 1981. Practical Human Biology. London; New York: Academic Press.

23. ***World Health Organization. 2010. Global Recommendations on Physical Activity for Health. Geneva: WHO Press. Available at: http://apps.who.int/iris/bitstream/10665/44399/1/9789241599979_eng.pdf [Accessed 12 September 2017]. 